\title{
Deactivation Modeling through Separable Kinetics of Coking On Ni/CZ Catalyst Used In SMR
}

\author{
Sudip Das \\ (Department of Chemical engineering, Indian Institute of Technology, Kharagpur, India-721302)
}

\begin{abstract}
Steam methane reforming (SMR) is a very significant technique to produce hydrogen from fossil fuels. In this particular work, nickel is used as the active metal and ceria-zirconia (CZ) bi-metallic oxide is used as the support. The foremost challenge to this process is sooting or coking over the catalyst surface and blocking the active sites. For the economic viability of the catalyst, it is very significant to make it coke deposition resistant. This is the reason that the kinetic modeling of the deactivation is very important. Therefore, this paper is aimed to model the deactivation and activity of the catalyst. A rate model of the deactivation process is also developed using separable kinetics. A comparison with commercial catalyst is also reported to show that the Ni/CZ catalyst is much more stable towards the coking.
\end{abstract}

Keywords -Coking, Deactivation, Methane, Separable kinetics, Steam reforming.

\section{Introduction}

In the present era high entity of pollution and subsequent global warming are the biggest threat to mankind. Since last three decades researchers worldwide are trying to find fuels which do not emit $\mathrm{CO}_{\mathrm{x}}$ $, \mathrm{NO}_{\mathrm{x}}, \mathrm{SO}_{\mathrm{x}}$ and VOC. Hydrogen (Calorific value $141.9 \mathrm{KJ} / \mathrm{g}$ ) is considered as the most energy efficient and pollution free fuel till date [1]. Fossil fuels undergo a specific type of reaction to produce Hydrogen which is known as reforming. Out of various kinds of reforming processes steam reforming is considered the best due to highest value $\mathrm{H}_{2} / \mathrm{CO}$ [2]. Methane which is the most important constituent of natural gas is used as the fossil fuel feedstock due to its easy availability and the fact that all other reforming hydrocarbon feeds like methanol, ethanol, propane, naphtha, etc. go through identical intermediates like ${ }^{*} \mathrm{CHO},{ }^{*} \mathrm{CH}_{2},{ }^{*} \mathrm{CH}_{2} \mathrm{O},{ }^{*} \mathrm{CH}_{4}$ etc as in the case of methane during the steam reforming process [3]. As far as the catalytic aspects of SMR are concerned, $\mathrm{Ni}$ is used as active metal and ceria - zirconia bi-metallic oxide (CZ) is used as catalytic support due to its high oxygen storage capacity (OSC) and high thermal endurance [4].

Deactivation of catalysts is a very significant event that happens during high temperature heterogeneous catalytic processes which involve carbonaceous components. Deactivation can happen via sintering, coking and poisoning [5]. Due to the absence of any catalyst poison in this particular case and higher thermal stability of $\mathrm{Ni} / \mathrm{CZ}$ catalyst, the chances of poisoning and sintering are considered as null. So coking is assumed to be sole responsible factor for catalyst deactivation. It is very important to apply a catalyst which is less deactivation prone and can act for a longer span.

To know the probability of deactivation through coking, making out of deactivation kinetics is very significant. There can be two kinds of deactivation kinetics, separable and inseparable form. In this particular work separable kinetics of deactivation has been followed. Also, activity of the catalyst and rate of deactivation are modeled.

\subsection{Catalyst preparation}

\section{Experimental Details}

$\mathrm{Ni} / \mathrm{CZ}$ catalyst was prepared via incipient wetness impregnation method. Zirconium precursor $(\mathrm{Zr}$ propoxide) was mixed with water and stirred for 30 minutes. The Ceria precursor (Ce-nitrate) was mixed with the mixture in a way such that the molar ratio of ceria and zirconium remained fixed $(0.2,0.5,1,2$, and 5$)$ and the solution was treated with $0.3-0.5$ moles of CTAB which was used as the template agent. The $\mathrm{pH}$ of the mixture was maintained at 9-9.5 using proper amount of ammonia solution or sodium carbonate. Nickel nitrate which was used as the nickel precursor, was added with a targeted $\mathrm{Ni}$ loading to this solution and stirred. Hydrazine hydrate ( $500 \mu \mathrm{l}$ using micropipette) was added to the solution mixture as the reducing agent. Then the sample was dried at $80^{\circ} \mathrm{C}$ overnight and calcined at $550^{\circ} \mathrm{C}$. Fig. 1 shows the schematic of the catalyst preparation procedure.

\subsection{Catalyst characterization}

For this particular work, the fresh catalyst sample was characterized by Scanning electron microscopy with energy dispersive X-ray spectrometry; Temperature programmed reduction and BET surface area analysis before and after the SMR experimentation. 


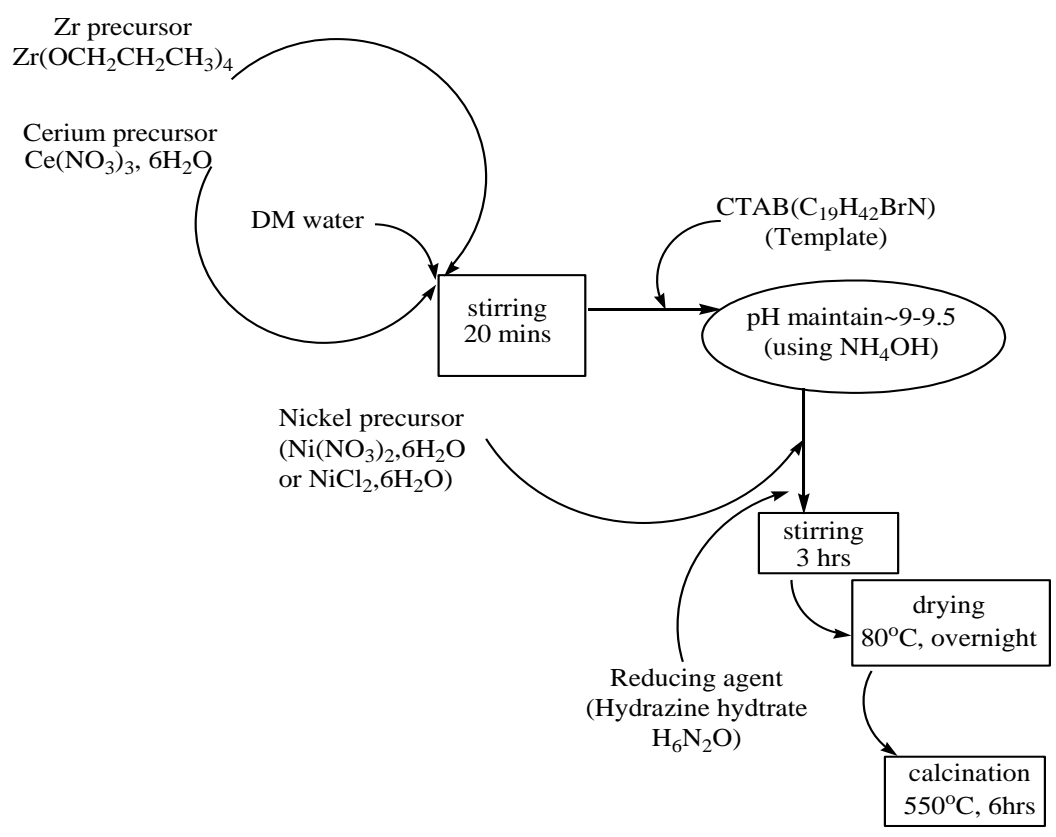

Fig.1. Schematic of catalyst preparation technique.

The microstructures, surface morphology and quantitative elemental distribution analysis of the catalyst were examined by Scanning Electron Microscopy (SEM) coupled with an X-ray Energy Dispersive Spectrometer (EDS). SEM and EDS X-ray measurements were performed using EV060 ZEISS and Oxford instrument, respectively, with an acceleration voltage of $20 \mathrm{kV}$. Before scanning process, all the samples were coated with gold in a vacuum sputter coater. The surface area, average pore diameter and the pore volume were determined by Nitrogen physisorption. The specific surface area was calculated by the Brunauer-Emmett-Teller (BET) method to the nitrogen adsorption isotherms obtained at liquid nitrogen temperature. The average pore diameter was determined by applying the Barret-Joyner-Halenda (BJH) method. BET surface area was measured by using a Quantachrome AUTOSORB 1 instrument by adsorption of nitrogen at $77 \mathrm{~K}$ on $200 \mathrm{mg}$ of sample previously degassed at $473 \mathrm{~K}$ for $2 \mathrm{~h}$ under high vacuum. Temperature-programmed reduction (TPR) is a technique for the characterization of solid materials and is often used in the field of heterogeneous catalysis to find the most efficient reduction conditions. The Chemisorption analyser (Micrometrics Autochem II, Micrometrics, USA) was used to know the optimum catalyst activation temperature. A gas mixture of $10 \%$ (V/V) hydrogen in nitrogen was used along with a heating value of $10 \mathrm{~K} / \mathrm{min}$.

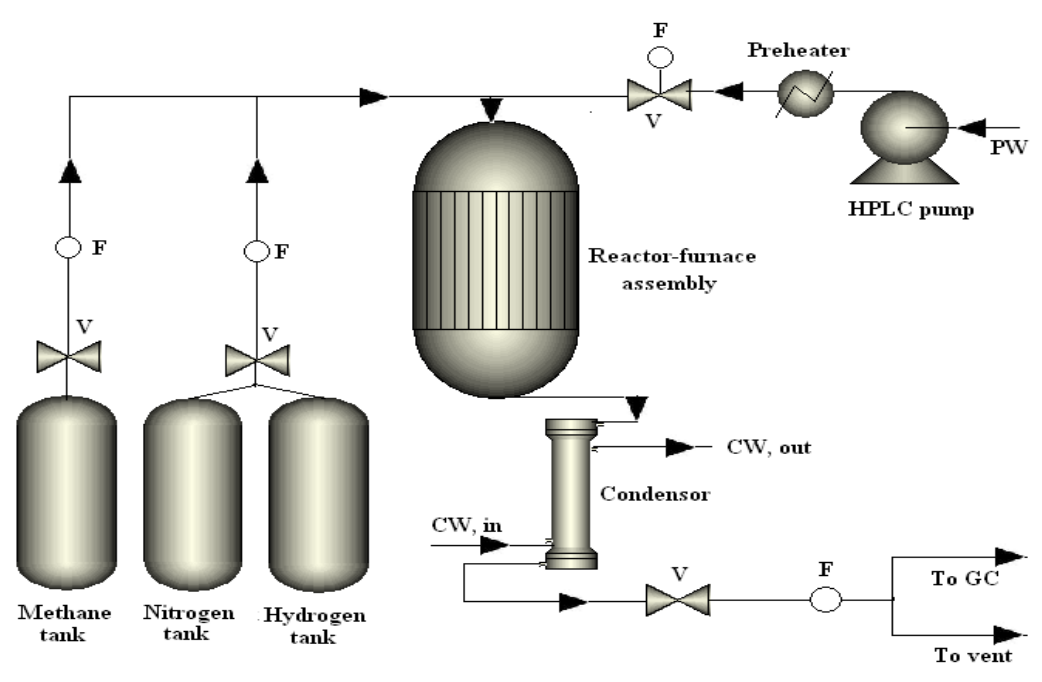

Fig.2. flow diagram of SMR experimental process (F- flowmeter, V- valve, $\mathrm{PW}$ - process water, CW- cooling water, GC- gas chromatography). 


\subsection{SMR experimentation}

The setup consisted of a gas feeding system, liquid feeding system, pre-heater, reactor-furnace assembly, condenser, gas liquid separator, wet gas meter, control system and the necessary piping and related instrumentation. The products were analyzed using an online GC with a thermal conductivity detector (TCD). The gas feeding system consists of gas cylinder of Hydrogen(XL grade, 99.9\% purity), methane (XL grade, 99.9\% purity) supplied by M/S BOC Gas Pvt. Ltd. The experimental rig consists of two mass flow controllers, one for hydrogen and another for methane. A schematic diagram of the experimental set-up is shown in Fig. 2.The liquid feeding system consists of two feed vessels placed on weighing scale, two HPLC (High Pressure Liquid Chromatography) pumps and pre-heater. The liquid feed (water in the present study) was vaporized by means of pre-heater in the upstream of reactor inlet. The main part of the steam reforming unit is reactor-furnace assembly. Reactor of inner diameter $10 \mathrm{~mm}$ was used in steam reforming experiment. The reactor was made of tubes of high quality stainless steel designed to withstand a temperature of $1000^{\circ} \mathrm{C}$. The reactor consists of a thermo-well inside the tube for recording of catalyst bed temperature. Downstream assembly consists of a double pipe heat exchanger (condenser) connected to the downstream of reactor for cooling the product stream. Cooling water is supplied in the counter current mode to condenser. The condensed product was collected in a gas-liquid separator. The product gas flow was measured by a wet gas meter before being vented out.

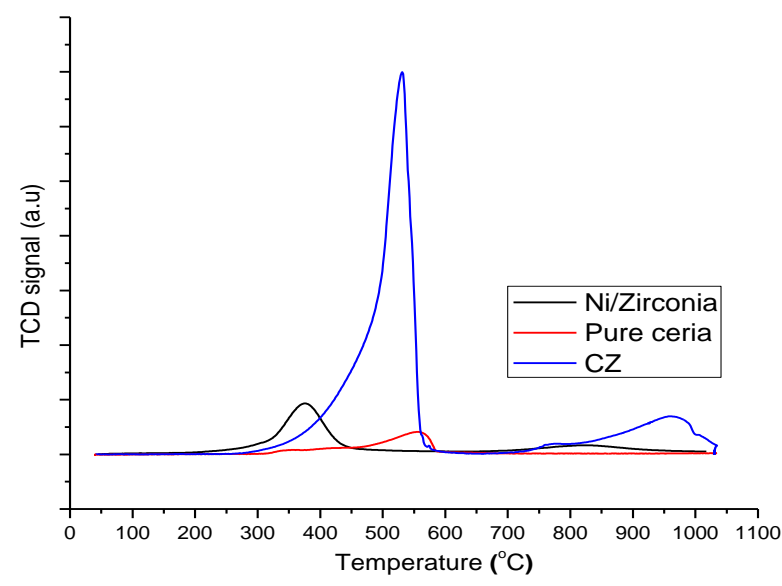

Fig.3. TPR profiles of prepared catalyst samples.

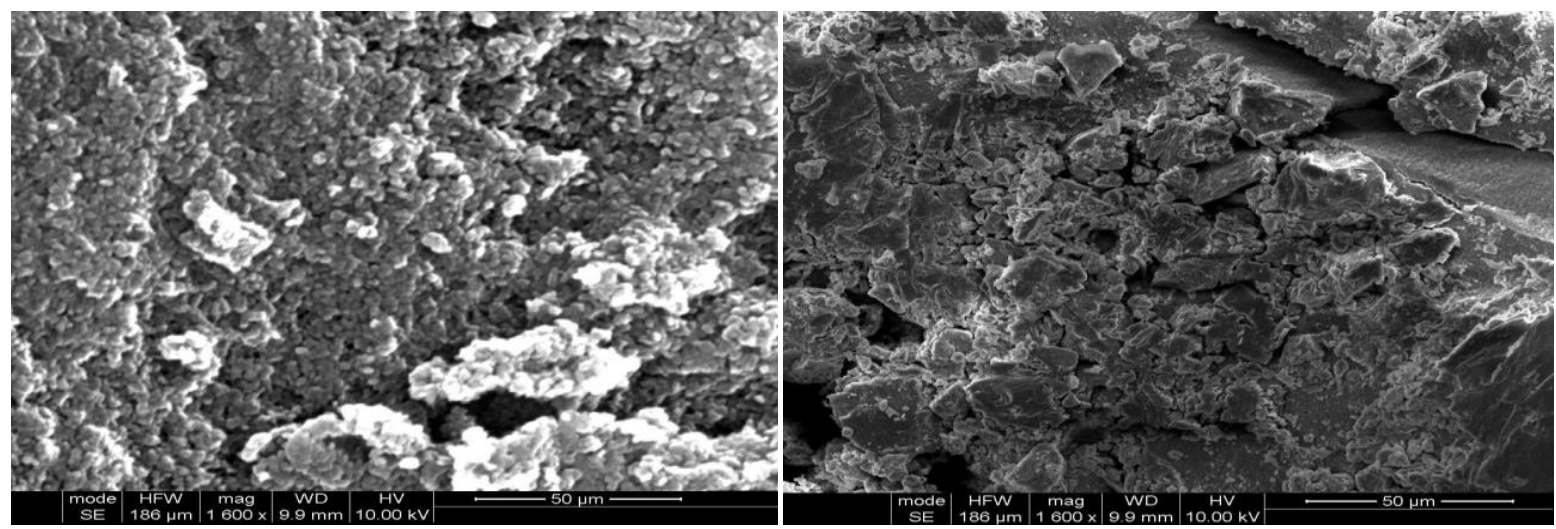

Fig.4. SEM images of catalyst sample (Left: fresh catalyst, Right: spent catalyst)

\subsection{Product analysis}

The online Gas Chromatograph (Model: GC 1000 DPR) procured from M/s Chemito Technologies Pvt. Ltd., equipped with a sampling valve (with heating oven), two columns and thermal conductivity detector (TCD) was used for the analysis of liquid and gaseous products. The gaseous products were analyzed using a Spherocarb column (1/8' diameter and length 8') and the liquid products were analyzed using a Porapack Q (1/8" diameter and length 6') column. Nitrogen (99.9\% purity) was used as the carrier gas at a flow rate of 35 $\mathrm{cm}^{3} / \mathrm{min}$. The GC was calibrated periodically using a calibration gas mixture consisting of $\mathrm{H}_{2}=47.71 \%$, 
$\mathrm{CO}=20.82 \%, \mathrm{CH}_{4}=47.71 \%$ and $\mathrm{CO}_{2}=21.86 \%$ (all values in v/v) procured from M/s Alchemie Gases and Chemicals Pvt. Ltd., India.

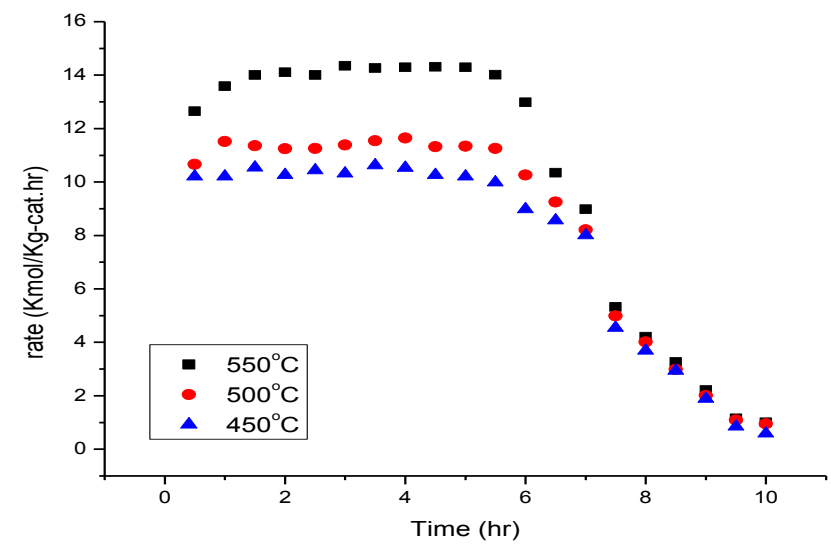

Fig.5. Result of TOS studies of prepared catalyst

(S/C feed molar ratio: 6:1, 10\% Ni loading, Space-time: $5.56 \mathrm{Kg}$-cat.hr/mole of methane)

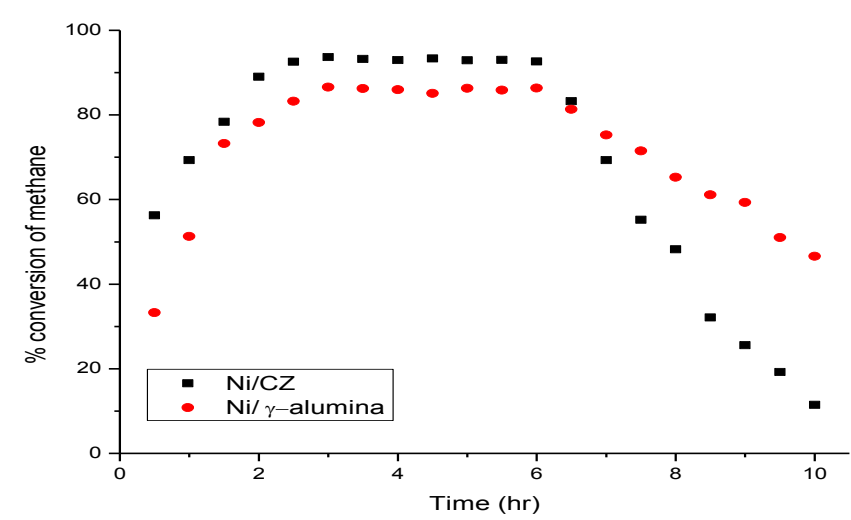

Fig.6. Result of TOS studies of prepared catalyst and commercial catalyst. (10\% Ni loading, 6:1 S/C feed molar ratio,

$550^{\circ} \mathrm{C}$ reaction temperature, Space-time: $5.56 \mathrm{Kg}$-cat.hr/mole of methane).

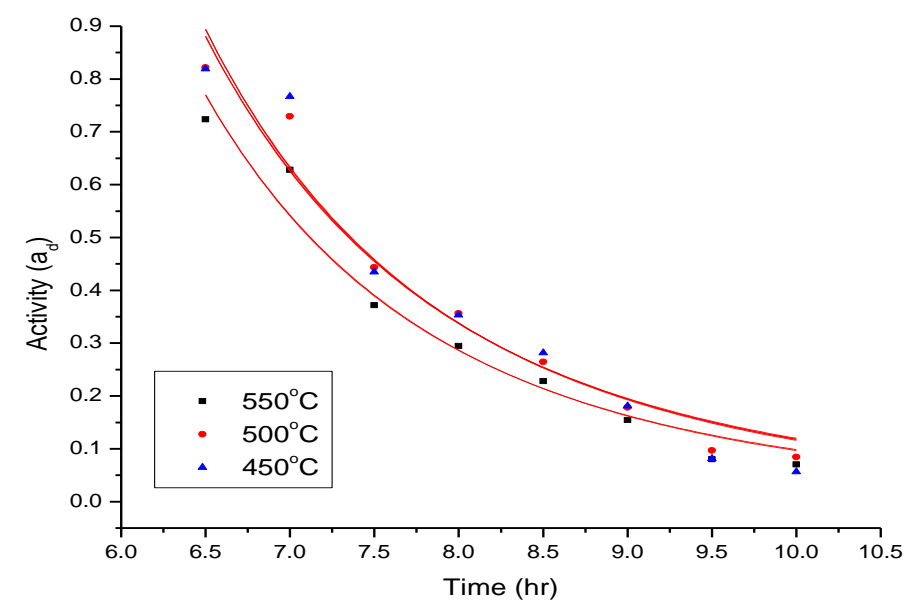

Fig.7. Result of curve fitting for activity with respect to TOS (Function: $\left.\mathrm{a}_{\mathrm{d}}(\mathrm{t})=\mathrm{A}(1+\mathrm{t})^{\mathrm{m}}\right)$ 


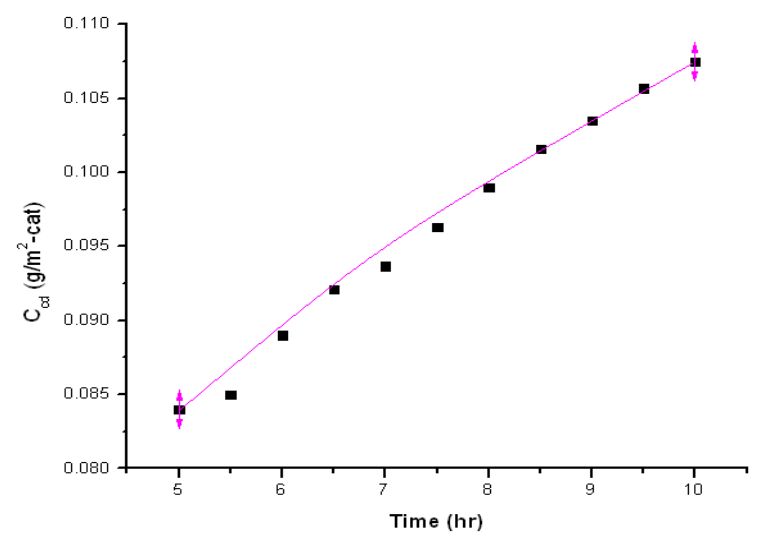

Fig.8. Result of TOS study and curve fitting to estimate Voorhies's parameters (B and n)

(S/C feed molar ratio: 6:1, 10\% Ni loading, Space-time: $5.56 \mathrm{Kg}$-cat.hr/mole of methane)

\section{Results And Discussions}

Fig. 3 shows the TPR profiles of the preparedcatalyst. TPR profiles are very significant for selecting the activation temperature of the catalyst before actual steam reforming runs. The TPR profiles reveal that $\mathrm{Ni}$ catalyst in the form of $\mathrm{NiO}$ can be activated within the temperature range of $350-380^{\circ} \mathrm{C}$, whereas, ceria and zirconia components are having the hydrogen chemisorption temperature at $500-550^{\circ} \mathrm{C}$ and $>700^{\circ} \mathrm{C}$ respectively. Higher thermal stability of zirconia than ceria is observed as expected. Hence, the activation temperature of the prepared catalyst is reported as $350-380^{\circ} \mathrm{C}$.

Fig. 4 illustrates sooting over the catalyst surface. The SEM images of fresh catalyst and spent catalyst clearly indicate coke deposition over the active sites of the catalyst. Results of EDS in TOS studies have been reported in Table which reveals the extent of coking with time.

The effect of coking is also brought to view via the BET-BJH surface area analyses of fresh and spent catalyst in Table-1. Pore volume and average pore diameter have decreased significantly after the SMR experimentation due to coking and subsequent pore blockage.

Fig. 5 shows the TOS studies of prepared catalyst for three different temperatures $\left(450-550^{\circ} \mathrm{C}\right)$. It can be seen that, up to $4.5 \mathrm{hrs}$, the rate remained almost constant and beyond $5 \mathrm{hrs}$, there was a significant continuous drop of rate with time. This happened due to extensive coking over the catalyst surface.

The result of comparison in terms of methane conversion with varying TOS is shown in Fig. 6. It can be observed that the achieved maximum methane conversion is higher in the case of prepared $\mathrm{Ni} / \mathrm{CZ}$ catalyst whereas the durability is to be enhanced to make it economically viable.

\subsection{Model Description}

\section{Deactivation Model}

Separable kinetic model was applied for the deactivation modeling [6]. First of all it was assumed that deactivation happened only because of coking. As the thermal endurance limit of FMWCNT is around $1000^{\circ} \mathrm{C}$, and there was no detection of presence of catalyst poisons, the assumption obtained qualitative validation.

First of all, activity of the catalyst is defined as the ratio of rate at any time $=\mathrm{t}$ to the corresponding initial rate. $a_{d}(t)=r_{t} / r_{o}$

Consecutively, the deactivation rate $\left(r_{d}\right)$ can be represented as,

$-\frac{\mathrm{da}_{\mathrm{d}}}{\mathrm{dt}}=\mathrm{r}_{\mathrm{d}}$

The amount of coke on the surface after a time $t$ has been found to obey the following empirical relationship, which was originally developed by Voorhies [7] and has been found to hold for a wide variety of catalysts and feed streams.

$\mathrm{C}_{\mathrm{c}}=\mathrm{Bt}^{\mathrm{n}}$

Where, $\mathrm{B}$ and $\mathrm{n}$ are model parameters.

\subsection{Results and discussions}

From Fig. 5 it can be concluded that the deactivation of the catalyst started beyond $6.5 \mathrm{hrs}$. So the activity of the catalyst was measured for the span of 6.5-10 hrs. The initial rate for a particular temperature was assumed to be the average rate for the span 0-6.5 hrs. Activity of the catalyst were found out and fitted as a function of time for three different temperatures. 
Activity was fitted to the equation (see Fig. 7):

$a_{d}(t)=A(1+t)^{m}$

And the values of estimated parameters are shown in Table-2. Hence the deactivation rate becomes, $r_{d}(t)=A m(1+t)^{m-1}$

From EDS analysis of spent catalysts (see Table-3), amount of deposited coke was estimated empirically. Those values were used to estimate the values of B and n. Fig. 8 shows the result. Estimated values (using curve fitting technique) of $\mathrm{B}$ and $\mathrm{n}$ are found as $\mathrm{B}=0.045, \mathrm{n}=0.38$.

\section{Conclusion}

Though SMR technique for the production of hydrogen for different purposes is a common practice since last 2-3 decades but due to some major problems and challenges like high amount of $\mathrm{CO}_{\mathrm{x}}$ formation, less catalyst durability due to sooting, research is still progressing all around the globe. In this work, a quantitative modeling on the deactivation through coking over the SMR catalyst (Ni/CZ) has been reported. 3-4\% of average

Table-1. BET-BJH surface area analysis results of fresh and spent catalyst.

\begin{tabular}{|c|c|c|}
\hline Property & Fresh catalyst & Spent catalyst \\
\hline BET surface area & $197.2840 \mathrm{~m}^{2} / \mathrm{g}$ & $20.1470 \mathrm{~m}^{2} / \mathrm{g}$ \\
\hline Micropore area & $21.0831 \mathrm{~m}^{2} / \mathrm{g}$ & $4.9632 \mathrm{~m}^{2} / \mathrm{g}$ \\
\hline External surface area & $176.2009 \mathrm{~m}^{2} / \mathrm{g}$ & $15.1838 \mathrm{~m}^{2} / \mathrm{g}$ \\
\hline Micropore volume & $0.303979 \mathrm{cc} / \mathrm{g}$ & $0.002174 \mathrm{cc} / \mathrm{g}$ \\
\hline Average pore diameter & $17.16327 \mathrm{~nm}$ & $9.82337 \mathrm{~nm}$ \\
\hline
\end{tabular}

Table-2. Result of parameter estimation.

\begin{tabular}{|c|c|c|}
\hline \multirow{2}{*}{$\begin{array}{c}\text { Temperature } \\
\left({ }^{\circ} \mathbf{C}\right)\end{array}$} & A & M \\
\cline { 2 - 3 } & $4.17 \mathrm{E} 04$ & -5.41 \\
\hline 550 & $3.45 \mathrm{E} 04$ & -5.24 \\
\hline 500 & $4.12 \mathrm{E} 04$ & -5.33 \\
\hline 450 &
\end{tabular}

Table-3. EDS studies of spent catalyst with respect to TOS

\begin{tabular}{|c|c|c|c|c|c|c|c|c|c|c|c|}
\hline TOS (hr) & 5 & 5.5 & 6 & 6.5 & 7 & 7.5 & 8 & 8.5 & 9 & 9.5 & 10 \\
\hline C (wt \%) & 2.61 & 2.99 & 4.16 & 4.68 & 5.36 & 5.99 & 7.32 & 8.11 & 9.35 & 10.23 & 11.98 \\
\hline
\end{tabular}

error came into picture as the consequence of the model assumptions and curve fitting. It has been assumed that coking happened only due to encapsulating coking and not because of filamentous coking. Also it has been assumed that there was no effect of sintering and poisoning, the argument behind these have been discussed earlier in this paper. In future, Langmuir-Hinshelwood mechanism or inseparable kinetics of deactivation can be incorporated into the same work. Yet, a descent model prediction and parameter estimation along with rigorous experimentation have been done.

\section{Acknowledgement}

The author would like to express the sincerest gratitude to Dr. Narayan C Pradhan (Professor, Department of Chemical Engg., Indian Institute of Technology, Kharagpur, West Bengal, India) and Dr. Rajaram Bal (NCA, CSIR-Indian Institute of Petroleum, Dehradun, Uttarakhand, India) for their technical supports. Above all, I am thankful to my family, whose blessings have always played a vital role in all the walks of my life.

\section{Nomenclature}

\begin{tabular}{|l|l|}
\hline Symbol & Significance \\
\hline $\mathrm{a}_{\mathrm{d}}$ & Activity of the catalyst \\
$\mathrm{A}, \mathrm{B}$ & Model parameters \\
$\mathrm{C}_{\mathrm{c}}$ & Concentration of deposited coke over catalyst surface $\left(\mathrm{g} / \mathrm{m}^{2}-\mathrm{cat}\right)$ \\
$\mathrm{m}, \mathrm{n}$ & Model parameters \\
$\mathrm{t}$ & Time $(\mathrm{hr})$ \\
$\mathrm{r}_{\mathrm{o}}$ & Initial rate of SMR reaction $(\mathrm{Kmol} / \mathrm{Kg}$-cat.hr) \\
$\mathrm{r}_{\mathrm{d}}$ & Rate of SMR reaction at any time $\mathrm{t}(\mathrm{Kmol} / \mathrm{Kg}$-cat.hr $)$ \\
$\mathrm{r}_{\mathrm{t}}$ & Rate of deactivation $\left(\mathrm{hr}^{-1}\right)$ \\
\hline
\end{tabular}




\section{REFERENCES}

[1] L. S. Neiva and L. Gama, A study on the characteristics of the reforming of methane: A review, Brazilian journal of petroleum and gas, 4(3), 2010, 119-127.

[2] P. van Beurden, On the catalytic aspects of steam-methane reforming, ECN-I, 4(3), 2004, 1-27.

[3] V. Mas, M. L. Bergamini, G. Baronetti, N. Amadeo and M. Laborde, A kinetic study of ethanol steam reforming using a nickel based catalyst, Top Catal, 51, 2008, 39-48.

[4] Prashant Kumar, Yanping Sun and Raphael O. Idem, Nickel-based ceria, zirconia, and ceria-zirconia catalytic systems for lowtemperature carbon dioxide reforming of methane, Energy \& Fuels, 21, 2007, 3113-3123.

[5] H. Scott Fogler, Elements of chemical reaction engineering, Fourth Ed. (New Delhi: Prentice-Hall India, 2008).

[6] G. F. Froment and K. B. Bischoff, Chemical reactor analysis and design, Second Ed. (Singapore: John Wiley and Sons, 1990).

[7] A. Voorhies, Ind. Eng. Chem.,37, 1945, 318-322. 